\title{
Frédéric Saumade et Jean-Baptiste Maudet, Cowboys, clowns et toreros. L'Amérique réversible
}

Paris, Berg international, 2014

\section{François Vatin}

\section{(2) OpenEdition}

\section{Journals}

Édition électronique

URL : https://journals.openedition.org/artefact/7344

DOI : $10.4000 /$ artefact.7344

ISSN : 2606-9245

Éditeur :

Association Artefact. Techniques histoire et sciences humaines, Presses universitaires du Midi

Édition imprimée

Date de publication : 18 juin 2015

Pagination : 236-238

ISBN : 978-2-271-08155-1

ISSN : 2273-0753

Référence électronique

François Vatin, «Frédéric Saumade et Jean-Baptiste Maudet, Cowboys, clowns et toreros. L'Amérique réversible», Artefact [En ligne], HS 01 | 2015, mis en ligne le 28 avril 2021, consulté le 05 mai 2021. URL : http://journals.openedition.org/artefact/7344 ; DOI : https://doi.org/10.4000/artefact.7344

Ce document a été généré automatiquement le 5 mai 2021.

Artefact, Techniques, histoire et sciences humaines est mise à disposition selon les termes de la Licence Creative Commons Attribution - Pas d'Utilisation Commerciale - Pas de Modification 4.0 International. 


\title{
Frédéric Saumade et Jean-Baptiste Maudet, Cowboys, clowns et toreros. L'Amérique réversible
}

Paris, Berg international, 2014

\author{
François Vatin
}

\section{RÉFÉRENCE}

Frédéric Saumade et Jean-Baptiste Maudet, Cowboys, clowns et toreros. L'Amérique réversible, Paris, Berg international, 2014, 343 p.

1 C'est un ouvrage dense, riche de données et de réflexions que nous livrent, sous ce titre énigmatique, Frédéric Saumade, professeur d'anthropologie à l'université d'AixMarseille, et Jean-Baptiste Maudet, maître de conférences de géographie à l'université de Pau. Tous les deux grands spécialistes (et passionnés) de la tauromachie, ils l'ont déjà étudiée sur les terrains européens (France, Espagne, Portugal) et latino-américains (Mexique, notamment). Ils se consacrent ici à l'Amérique du nord, où la tauromachie classique (avec mise à mort) est proscrite et où règne un spectacle taurin en apparence de nature toute différente, le rodéo. Leur terrain d'enquête est l'État de Californie. Ils présentent (p. 24) une carte de la dispersion des rodéos et jeux d'arène sur l'ensemble du territoire des États-Unis, qui montre la diffusion de ces festivités sportives du nord au sud et de l'est à l'ouest de la fédération. Elle témoigne que l'on trouve, sur le seul territoire californien, l'ensemble des types de rodéos qui se déploient à l'échelle du pays, ce qui en fait donc un territoire exemplaire pour une telle étude.

2 Les auteurs s'attachent, dans une première partie, à distinguer et décrire minutieusement les différentes variétés de rodéo qu'ils ont pu observer en Californie : rodéos " anglos ", " mexicains ", " blacks ", " indiens " et même " gays ». Ils montrent comment le spectacle de rodéo, emblématique en cela du modèle national américain, permet à la fois d'exalter la communauté d'appartenance et l'américanité. 
Ce parcours dans la "Californie profonde ", richement illustré de superbes photographies, où l'on voit, à travers les figures de style de la pratique des jeux taurins (et équestres), se distinguer, mais aussi se métisser, ces différentes communautés, est en soi déjà passionnant. On apprend la présence en Californie d'une puissante communauté lusitanienne originaire des Açores qui y domine l'élevage laitier. Cette communauté a importé dans la région la tradition tauromachique portugaise, dont l'influence est venue redoubler la tradition espagnole venue du Mexique (si l'on peut dire puisque la Californie américaine a fait partie de la Nouvelle Espagne, puis du Mexique jusqu'en 1848). On prend aussi connaissance de l'importance de la figure du clown dans les spectacles de rodéo. Outre celui qui est chargé de faire patienter le public entre les numéros, le "clown-torero » (bullfighters) a une fonction technique essentielle : détourner l'attention du taureau lorsque l'homme qui le chevauche, finalement projeté à terre, se trouve en danger. On mesure enfin le sort pitoyable de la plupart de ces compétiteurs, gladiateurs modernes, qui parcourent les États-Unis à leurs frais pour tenter d'obtenir les succès qui leur permettront de les couvrir et de subvenir à leurs besoins, tout en prenant le risque d'un accident grave et, en tous cas, celui d'une usure corporelle prématurée. Rares sont ceux qui font fortune à ce jeu, nous montrent les auteurs, et cette fortune est très modeste en comparaison de celles que peuvent générer d'autres sports.

3 Mais cette première partie ne constitue qu'une entrée en matière de l'ouvrage, dont la deuxième partie est consacrée aux traditions et techniques d'élevage bovin en relation avec la pratique des jeux taurins. On retrouve ici, dans leur fonction d'éleveurs, les héritiers des cowboys blancs, mais aussi les Lusitano-californiens et les indiens Yokut, qu'on a vus dans la première partie à l'œuvre dans les arènes. La compétence du géographe se combine remarquablement avec celle de l'anthropologue des techniques pour décrire les modalités d'élevage qui permettent, par la marchandisation de la reproduction et par une combinaison variable d'usages intensifs et extensifs de l'espace, de produire des bêtes combattantes, propres aux jeux taurins. On prend connaissance aussi d'étonnantes techniques d'alimentation du bétail, consistant soit, dans des univers extensifs et pauvres, à le laisser chercher lui-même une nourriture rare, ce qui le " fortifie ", soit, au contraire, dans des univers intensifs suburbains, à lui fournir des résidus de fruits et légumes de l'industrie agro-alimentaire ou même des déchets des plateaux-repas des avions. Les auteurs prennent soin de ne jamais céder au romantisme ou à l'exotisme de leur objet, pour bien ancrer leur analyse dans les pratiques matérielles, techniques, mais aussi économiques, qui font de la production des bêtes de scène une véritable industrie. Ils montrent les rapports contrastés avec les bêtes : la frontière entre les bêtes de combat et le bétail boucher est fragile et l'abattoir n'est jamais loin. Mais certaines bêtes valent d'abord pour leur pouvoir reproducteur et les meilleures, devenues symbole du troupeau, finissent de mort naturelle, enterrées sur l'exploitation.

4 C'est avec la troisième et dernière partie que l'on saisit l'ambition générale de l'ouvrage. Par un fin travail d'histoire et d'anthropologie comparée, les auteurs montrent, suivant leur formule, " comment le cowboy est né de la culture de ses ennemis " : c'est-à-dire, d'abord, les Indiens, qui ont su reporter sur les bovins leur art cynégétique élaboré dans la chasse aux cerfs et aux bisons et qui ont, en s'appropriant l'art équestre, en partie inventé la technique du lasso ; ensuite les Mexicains, qui furent les premiers éleveurs de bovins de la région bénéficiant de l'héritage de la riche tradition espagnole en la matière. Le cowboy blanc, repoussant la frontière de 
l'Amérique contre la sauvagerie indienne et refoulant l'hispanité au sud du Rio Grande, est en fait un être métissé. La re-latinisation actuelle de la Californie, du fait de l'importance de l'immigration mexicaine, s'inscrit dans un espace technique et culturel où l'hispanité n'a en fait jamais disparu. C'est donc, pour finir, à une réflexion sur la place de la « sauvagerie » dans la culture américaine que nous invitent les auteurs. Ils montrent que le puritanisme américain a toujours nourri son contraire, le goût du sauvage, dans des jeux permanents d'inversion, dont témoigne la tradition du cirque américain (Buffalo Bill), qui mit en scène de réels cowboys et de réels indiens. On retrouve ici l'importance de la figure du clown de rodéo, dont les auteurs font l'hypothèse que son origine se trouve en partie dans la culture indienne. C'est, pour finir, dans la tradition cinématographique américaine (dont les auteurs semblent aussi passionnés que de tauromachie) que Frédéric Saumade et Jean-Baptiste Maudet voient l'expression de cet "étrange goût de la défaite " qui caractériserait la culture américaine, entre puritanisme exacerbé et fascination pour la sauvagerie, surpuissance et soumission à la fatalité de l'apocalypse. Le rodéo, jeu où l'on entretient la sauvagerie de la bête pour montrer sa capacité à la dompter pendant les huit secondes réglementaires (règle du bull riding du rodéo " anglo " standard), pour la laisser retourner à son état de nature, ou prétendu tel, apparaît alors comme l'expression la plus condensée de l'Amérique dans tous ses états.

5 Cette rapide relation ne saurait rendre compte de la richesse de l'ouvrage qui peut se lire à de multiples niveaux. Les spécialistes d'anthropologie technique y trouveront notamment de multiples détails sur les techniques d'élevage des bovins, mais aussi des équidés, sur l'histoire des outils (lassos, piques, selles) en relation avec l'élevage bovin, mais aussi sur l'art tauromachique et celui du rodéo. C'est un ouvrage d'anthropologie au sens fort, où les dimensions techniques, économiques, symboliques d'une filière qui va de l'élevage à l'arène, sont toujours étroitement entremêlées. Sans doute, la contrepartie de cette richesse est le caractère foisonnant de l'ouvrage qui, pour satisfaire les différentes catégories de lecteurs potentiels, aurait pu être scindé en volumes distincts. Mais on peut se réjouir qu'il n'en soit rien, ce qui permet aux auteurs de rendre justice à toute l'épaisseur sociale de leur objet.

\section{AUTEURS}

\section{FRANÇOIS VATIN}

Université de Paris Ouest, IDHES UMR 8533 